\title{
A Sensitive Fluorescent Assay for Trypsin Activity in Biological Samples using BSA-Au Nanoclusters
}

\author{
Xianxiang Wang, * Yanying Wang, Hanbing Rao and Zhi Shan \\ College of Life and Science, Sichuan Agricultural University, 625014 Ya'an, Sichuan, P. R. China
}

\begin{abstract}
Neste artigo, foi desenvolvido um novo método fluorométrico, simples, sensível e seletivo, para a medição de tripsina em amostras biológicas. O método foi baseado na medição da supressão da intensidade da fluorescência de agregados de nanopartículas de ouro estabilizados com albumina sérica bovina (BSA), pela proteólise enzimática. A curva de calibração para tripsina foi atingida no intervalo de concentração de 1-60 nmol L-1 com coeficiente de correlação 0,995 e um limite de detecção de $0,6 \mathrm{nmol} \mathrm{L}^{-1}$. O método foi também usado satisfatoriamente para avaliação da atividade da tripsina e os resultados mostraram que os valores das constantes de Michaelis-Menten $\left(\mathrm{K}_{\mathrm{m}}\right)$ e catalítica $\left(\mathrm{K}_{\text {cat }}\right)$, de tripsina para estes substratos de nanoagreagados BSA-Au, foram $1,6 \times 10^{-5}$ mol L $\mathrm{L}^{-1}$ e $3,8 \mathrm{~s}^{-1}$ a $37^{\circ} \mathrm{C}$, respectivamente. Este biossensor enzimático é de interesse considerável devido à simplicidade do procedimento, e o método estabelecido tem grande potencial na detecção de outras proteases em diagnósticos clínicos de várias doenças.
\end{abstract}

A novel, simple, sensitive, and selective fluorometric method was developed for measuring trypsin in biological samples in this article. The method was based upon measuring the quenching of the fluorescence intensity of the bovine serum albumin (BSA) stabilized Au nanoclusters by enzymatic proteolysis. The calibration plot for trypsin was achieved over the concentration range 1-60 nmol L ${ }^{-1}$ with a correlation coefficient of 0.995 and a limit of detection of $0.6 \mathrm{nmol} \mathrm{L}^{-1}$. The method was also used satisfactorily for the assessment of the trypsin activity and the results showed that the Michaelis-Menten $\left(\mathrm{K}_{\mathrm{m}}\right)$ and catalytic $\left(\mathrm{K}_{\text {cat }}\right)$ constant values of trypsin for BSA-Au nanoclusters substrate were $1.6 \times 10^{-5} \mathrm{~mol} \mathrm{~L}^{-1}$ and $3.8 \mathrm{~s}^{-1}$ at $37^{\circ} \mathrm{C}$, respectively. This enzyme biosensor is of considerable interest due its promise for simple procedure and the established method has great potential in detection of other proteases in clinical diagnostics of various diseases.

Keywords: BSA-Au nanoclusters, trypsin, fluorescence, enzyme activity

\section{Introduction}

Trypsin is a catalyst for the hydrolysis of amide bonds in peptides and proteins, which plays an important role in numerous important physiological processes such as protein turnover, digestion, cell differentiation and growth, immunological defense, cancer, and apoptosis. ${ }^{1}$ Consequently, the monitoring of trypsin activity plays a central role in biochemical, pharmaceutical, and in the clinical application. The most common methods for detection degradative enzyme activity utilize fluorogenic ${ }^{2}$ or chromogenic substrates ${ }^{3}$ or fluorescence resonant energy transfer-based substrates ${ }^{4}$ or surface acoustic wave-impedance sensor. ${ }^{5}$ Unfortunately, these methods require considerable sample preparation and sophisticated

*e-mail: xianxiangwang@hotmail.com instrumentation, thereby making the assays timeconsuming, costly and error-prone. Furthermore, these methods do not meet the performance parameters necessary for rapid detection of low levels of enzyme activity directly in biological samples, making them unsuitable for pointof-case diagnostic applications.

To overcome these difficulties, it is important to develop a more efficient and simple method for monitoring the trypsin activity in biological samples. Among the reported methods for detecting enzyme activity, fluorometric analysis offers apparent advantage over other methods, such as electrophoretic method, ${ }^{6,7}$ by virtue of their sensitivity and convenience. This method always relies on monitoring the fluorescence intensity as a result of enzymatic substrate proteolysis in the solution. The key success factor of this method is the fluorescent substrate. Hence, building a more suitable fluorescent substrate for the special enzyme is very 
necessary. Bovine serum albumin (BSA) is used generally as a model protein substrate to study the proteases activity, but these methods exclude fluorometric analysis because itself has no fluorophore. Recently, natural and efficient biosynthesis of the unique fluorescent nanomaterials have gained increasing interest for many scientists. ${ }^{8-10}$ Among fluorescent nanomaterials, BSA-templated Au nanoclusters are of particular interest due to their facile synthesis, red emission, high quantum yield and good biocompatibility. ${ }^{10}$ The prepared BSA-Au nanoclusters formed in the BSA solution could have been stabilized by a combination of $\mathrm{Au}-\mathrm{S}$ bonding with the protein (via the 35 Cys residues in BSA), and the steric protection due to the bulkiness of the protein. If the surrounding BSA biomolecules is destroyed by other reagents, the fluorescence intensity of the $\mathrm{Au}$ nanoclusters will be decreased, for example, the cases of $\mathrm{Cu}^{2+}$ and glutathione (GSH)-Au nanoclusters, ${ }^{11}$ or hydrogen peroxide and BSA-Au nanoclusters. ${ }^{12}$ Since trypsin is an efficient hydrolase for BSA digestion, the structure of the BSA-Au nanoclusters will be destroyed in the present of trypsin. Therefore, this enzymatic proteolysis reaction will decrease the fluorescence of BSA-Au nanoclusters. Inspired by this observation, we herein used originally the fluorescent BSA-Au nanoclusters as a probe to measure the trypsin activity in biological samples. Furthermore, this assay is simple, fast and sensitive.

\section{Experimental}

\section{Chemicals and apparatus}

Bovine serum albumin (BSA) and trypsin from bovine pancreas (T1426, activity about 10,000 units per $\mathrm{mg}$ proteins) were bought from Sigma-Aldrich (China). $\mathrm{HAuCl}_{4} \cdot 3 \mathrm{H}_{2} \mathrm{O}$ and other salts were purchased from Kelong Reagent Co., Chengdu, China. All other chemicals, such as sodium hydroxide, were of analytical grade and used without further purification. All solutions were prepared with water purified by a Milli-Q purification system (Millipore, USA).

Fluorescence measurements were conducted with a Thermo Electron Varioskan (Thermo Fisher Scientific Inc.) spectral multimode reader using 384-well fluorescence plates, the excitation and emission wavelengths is 370 $\mathrm{nm}$ and $621 \mathrm{~nm}$, respectively. UV-Vis absorption spectra were recorded by using a SHIMADZU UV-Vis 2450 spectrophotometer (Japan). The molecular weights of BSA and BSA-Au nanoclusters were analyzed with matrix-assisted laser desorption/ionization-time-of-flight (MALDI-TOF) mass spectrometry on a Bruker Daltonics Autoflex II TOF/TOF system (Germany). PHS-3E pH meter (Shanghai Feile Co., Ltd., China) was used during the preparation of buffers.

\section{Synthesis of red fluorescent BSA-Au nanoclusters}

Red fluorescent BSA-stabilized Au nanoclusters was synthesized in aqueous solution following a previous reported method. ${ }^{10}$ In a typical experiment, all glassware used in the experiments were cleaned in a bath of freshly prepared aqua regia $\left(\mathrm{HCl}: \mathrm{HNO}_{3}, 3: 1, \mathrm{v} / \mathrm{v}\right)$, and rinsed thoroughly in water prior to use. $\mathrm{HAuCl}_{4}$ solution $(15 \mathrm{~mL}$, $\left.10 \mathrm{mmol} \mathrm{L}-1,37^{\circ} \mathrm{C}\right)$ was added to BSA solution $(15 \mathrm{~mL}$, $\left.50 \mathrm{mg} \mathrm{mL}^{-1}, 37^{\circ} \mathrm{C}\right)$ under magnetic stirring. Then, $\mathrm{NaOH}$ $\left(1 \mathrm{~mol} \mathrm{~L}{ }^{-1}, 1.5 \mathrm{~mL}\right)$ solution was introduced and the mixture was allowed to incubate at $37{ }^{\circ} \mathrm{C}$ under vigorous magnetic stirring for $24 \mathrm{~h}$. The colour of the solution changed from light yellow to deep brown. The solution was then dialyzed in double distilled water for $48 \mathrm{~h}$ to remove unreacted $\mathrm{HAuCl}_{4}$ or $\mathrm{NaOH}$. The final solution was stored at $4{ }^{\circ} \mathrm{C}$ in refrigerator when not in use.

Procedures for trypsin activity assay

Trypsin activity assays were conducted at $30{ }^{\circ} \mathrm{C}$ with $0.1 \mathrm{mmol} \mathrm{L}^{-1} \mathrm{BSA}-\mathrm{Au}$ nanoclusters substrate in $10 \mathrm{mmol} \mathrm{L}^{-1}$ phosphate buffered saline (abbreviated PBS), $\mathrm{pH} 7.2$, and $100 \mathrm{mmol} \mathrm{L}^{-1} \mathrm{NaCl}$. A $50 \mu \mathrm{L}$ aliquot of BSA-Au nanoclusters was added and incubated for $10 \mathrm{~min}$, and then the fluorescence intensity was recorded by Thermo Electron Varioskan spectral multimode reader using 384-well fluorescence plates. Next, an aliquot of trypsin solution was added, and the fluorescence intensity was recorded automatically at set intervals. Then, the fluorescence intensities were converted to substrate concentration as a function of time by using equation 1 , which is derived from the Stern-Volmer equation.

$\left[\mathrm{Q}_{\mathrm{t}}\right]=\left[\mathrm{Q}_{0}\right]\left(1-\mathrm{I}_{\mathrm{t}} / \mathrm{I}_{0}\right)$

In equation $1,\left[\mathrm{Q}_{\mathrm{t}}\right]$ is the $\mathrm{BSA}-\mathrm{Au}$ nanoclusters concentration at time $t,\left[\mathrm{Q}_{0}\right]$ is the initial $\mathrm{BSA}-\mathrm{Au}$ nanoclusters concentration, $\mathrm{I}_{\mathrm{t}}$ is the fluorescence intensity at time $t$ after trypsin addition and $I_{0}$ is the initial fluorescence intensity of the BSA-Au nanoclusters. From the slope of this plot in the equation 1, the activity of the enzyme was calculated in the usual way. The MichaelisMenten $\left(\mathrm{K}_{\mathrm{m}}\right)$ and catalytic $\left(\mathrm{K}_{\mathrm{cat}}\right)$ constant values were determined by Lineweaver-Burk regression. $\mathrm{K}_{\text {cat }}$ is defined as $\mathrm{V}_{\max }$ /[enzyme].

To detect trypsin in biological samples, fresh healthy human blood plasma were obtained from community 
hospital. The plasma were used directly and diluted 100 times with ultrapure water before analysis. $100 \mu \mathrm{L}$ of $1 \mu \mathrm{mol} \mathrm{L}{ }^{-1} \mathrm{BSA}$-Au nanoclusters and $900 \mu \mathrm{L}$ diluted plasma solution were mixed thoroughly, and left for another $10 \mathrm{~min}$ to measure the fluorescence. Then, an aliquot of trypsin were added in the mixed solution and left for another $5 \mathrm{~min}$ to detect the fluorescence intensity.

\section{Results and Discussion}

\section{Characterization of BSA-Au nanoclusters}

The aqueous solution of as-prepared BSA-Au nanoclusters was deep brown in color and exhibited bright-red fluorescence under ultraviolet light. The spectral characteristics of the BSA-Au nanoclusters are consistent with the literature. ${ }^{10}$ The absorbance and emission spectra of the BSA-Au nanoclusters (Figure 1) show that the emission spectrum of the BSA-Au nanoclusters displayed about $620 \mathrm{~nm}$ upon excitation at $370 \mathrm{~nm}$. Referred to previously studies, BSA-Au nanoclusters were formed in situ by reduction the entrapped $\mathrm{Au}$ ions with the activated BSA molecules, and the Au nanoclusters formed in the BSA solution could have been stabilized by a combination of Au-S bonding with the protein (via the 35 Cys residues in BSA). MALDI-TOF mass spectrometry (Figure 2) confirmed that the BSA molecular weight was about $66 \mathrm{kDa}$, and the prepared BSA-Au nanoclusters showed a peak shift of about $5 \mathrm{kDa}$, which was attributed to the 25 gold atoms in the nanoclusters, and the structure is highly stability, and corresponded to the most common magic cluster size.

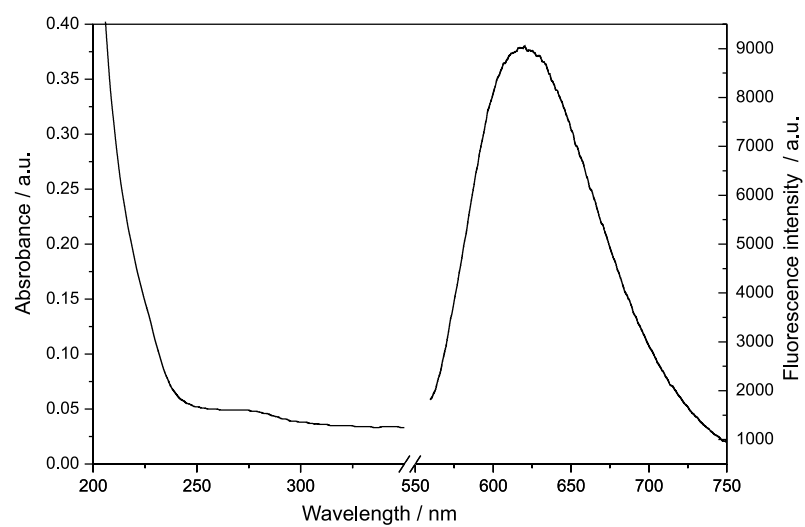

Figure 1. Absorption and fluorescence spectra of BSA-Au nanoclusters. All solutions were prepared using PBS buffer solution at pH 7.4.

\section{Effect of foreign species and other proteases}

The validity and selectivity of the developed fluorescence method was tested by studying the influence of a series of potentially interfering species co-existed in biological

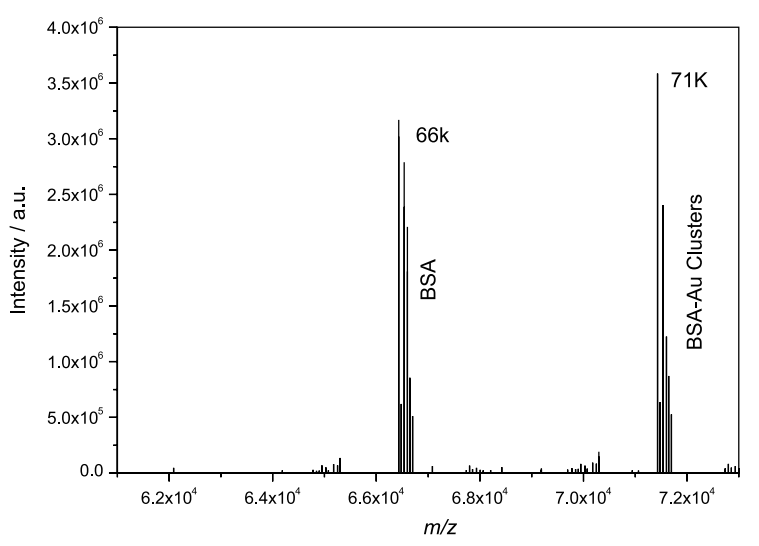

Figure 2. MALDI-TOF mass spectra of BSA and BSA-Au nanoclusters.

samples, e.g., $\mathrm{NaCl}, \mathrm{KCl}, \mathrm{CaCl}_{2}, \mathrm{MgCl}_{2}$, and $\mathrm{AlCl}_{3}$, uric acid, urea and glucose. The concentration of these foreign species was 100 -fold than the trypsin $\left(1 \mathrm{mmol} \mathrm{L}^{-1}\right)$ in PBS buffer of $\mathrm{pH} 7.4$ at $10 \mathrm{~min}$ contact time at $37{ }^{\circ} \mathrm{C}$ with $1 \mathrm{mmol} \mathrm{L}^{-1}$ BSA-Au nanoclusters. Figure 3a reveals that no significant change on the fluorescence intensity of BSA-Au nanoclusters in the presence of the tested interfering species except trypsin. The interaction between BSA-Au nanoclusters and other proteases was also studied. Figure $3 \mathrm{~b}$ showed that no obvious decrease in fluorescence intensity by adding other proteases, such as lysozyme, thrombin, pepsin, bromelain, papain and glucose oxidase (GOx). These results demonstrated that the enzymolysis of the BSA-Au nanoclusters by trypsin specifically caused the decrease in fluorescence intensity, and the BSA-Au nanoclusters could be used as a fluorescent probe for the sensitive detection of trypsin with minor interference from other proteases.

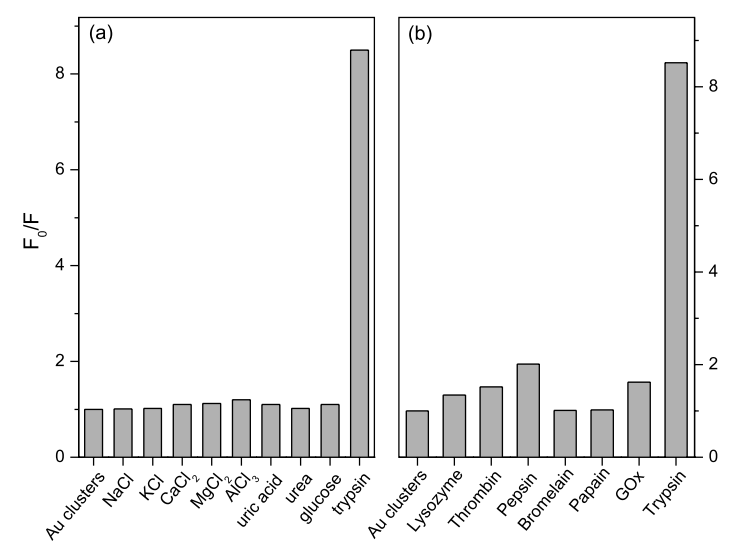

Figure 3. (a) Effect of foreign species and (b) other proteases toward $1 \mathrm{mmol} \mathrm{L}^{-1} \mathrm{BSA}-\mathrm{Au}$ nanoclusters by monitoring the relative fluorescence intensity $\mathrm{F}_{0} / \mathrm{F}$ (where $\mathrm{F}_{0}$ and $\mathrm{F}$ is the fluorescence intensity in the absence and in the presence of foreign species, respectively). The foreign species and other proteases concentrations were as follows: $100 \mathrm{mmol} \mathrm{L}^{-1}$ $\left(\mathrm{NaCl}, \mathrm{KCl}, \mathrm{CaCl}_{2}, \mathrm{MgCl}_{2}, \mathrm{AlCl}_{3}\right.$, uric acid, urea and glucose, lysozyme, thrombin, pepsin, bromelain, papain, glucose oxidase (GOx)) and $1 \mathrm{mmol} \mathrm{L}^{-1}$ trypsin. 


\section{Trypsin activity assays}

The BSA-stabilized Au nanoclusters can be hydrolyzed by trypsin. Figure 4 shows that the fluorescence intensity of prepared BSA-Au nanoclusters remains stable due to high resistance to photobleaching, which decreased only about $2 \%$ within $5 \mathrm{~min}$. However, with the addition of trypsin, a concentration dependent decrease in fluorescence is observed, and more enzymes were favorable to enzymatic proteolysis.

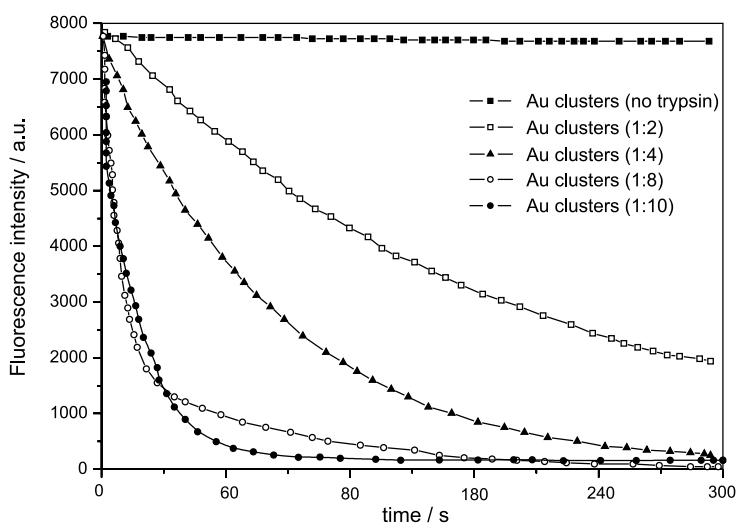

Figure 4. Fluorescence decay of BSA-Au clusters with variable amounts of trypsin.

From the time-course experiment (Figure 5a), we found that the rate of hydrolysis increased linearly with time of incubation for more than $1 \mathrm{~min}$ when the trypsin concentration was $0.001 \mathrm{mmol} \mathrm{L}^{-1}$ of reaction solution and BSA-Au nanoclusters concentration was $0.025 \mathrm{mmol} \mathrm{L}^{-1}$. Simultaneously, linearity was observed between relative

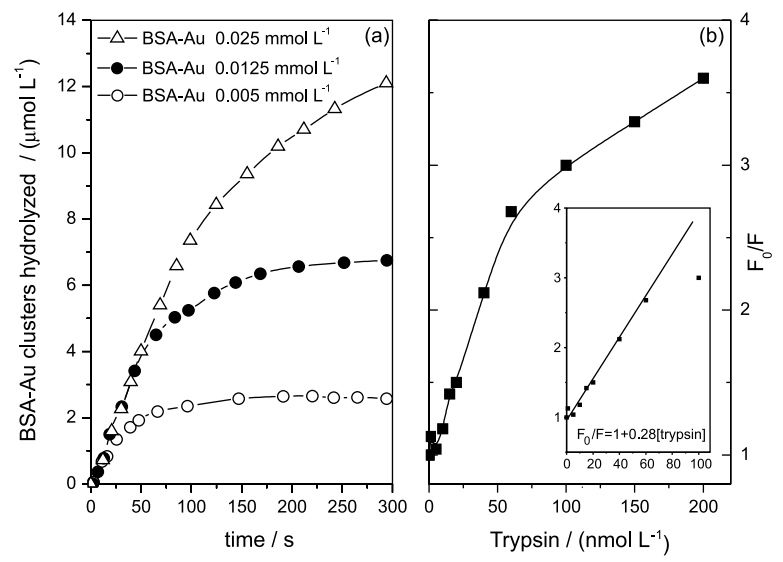

Figure 5. (a) Hydrolysis of BSA-Au nanoclusters by trypsin. Trypsin concentration was $0.001 \mathrm{mmol} \mathrm{L}^{-1}$ of reaction solution and BSA-Au nanoclusters concentration was varied with $0.005,0.0125$ and $0.025 \mathrm{mmol} \mathrm{L}^{-1}$. (b) $\mathrm{F}_{0} / \mathrm{F}$ upon the interaction of BSA-Au nanoclusters with different amount of trypsin. The inner graph shows the linear plot that reveals detectable concentration range of 1-60 nmol L-1 and the linear coefficient is 0.995 , where $\mathrm{F}_{0}$ and $\mathrm{F}$ are the relative fluorescence intensities of BSA-Au nanoclusters in the absence and in the presence of trypsin with incubation at $37^{\circ} \mathrm{C}$ for $2 \mathrm{~min}$.

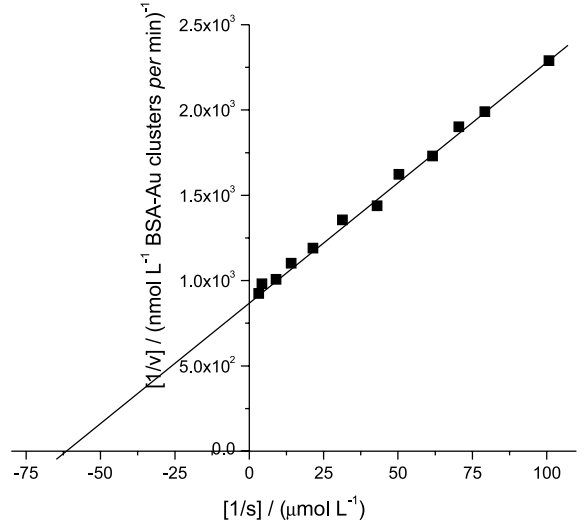

Figure 6. Lineweaver-Burk plot of hydrolysis of BSA-Au nanoclusters by trypsin. The initial velocity at each substrate concentration was determined after $10 \mathrm{~min}$ of incubation with $5 \mathrm{mg}$ of trypsin.

fluorescence intensity $\left(\mathrm{F}_{0} / \mathrm{F}\right)$ and the trypsin concentration over the range of 1 to $60 \mathrm{nmol} \mathrm{L}^{-1}$ (Figure $5 \mathrm{~b}$ ), with a correlation coefficient of 0.995 . The limit of detection $(\mathrm{LOD})$ is defined by the equation $\mathrm{LOD}=(3 \sigma / \mathrm{k})$, where $\sigma$ is the standard deviation of blank measurements $(n=11)$ and $\mathrm{k}$ is the slope of calibration graph. Here LOD was $0.6 \mathrm{nmol} \mathrm{L}{ }^{-1}$. So, this novel approach has potential to fast and quantitatively detect trypsin in biological samples.

Kinetic constants were derived from a double-reciprocal plot by the Lineweaver-Burk method and are based on the average of triplicate determinations. Figure 6 showed that the $\mathrm{K}_{\mathrm{m}}$ and $\mathrm{K}_{\mathrm{cat}}$ values for the hydrolysis of as-prepared BSA-Au nanoclusters were $1.6 \times 10^{-5} \mathrm{~mol} \mathrm{~L}^{-1}$ and $3.8 \mathrm{~s}^{-1}$ at $37{ }^{\circ} \mathrm{C}$. The $\mathrm{K}_{\mathrm{m}}$ value was much smaller than other reported fluorogenic substrates, ${ }^{13,14}$ indicating that trypsin has high affinity to the BSA-Au nanoclusters as compared with other substrates.

\section{Analytical applications}

In order to demonstrate the potential application of the proposed method for trypsin assays in clinical diagnosis, the biological samples were prepared by adding fixed amount of trypsin into human blood plasma taken from four healthy volunteers. The results are shown in Table 1. The accuracy of the method was investigated by recovery studies. The

Table 1. Analytical results (mean $\pm s ; n=3$ ) for the determination of trypsin in healthy human blood plasma

\begin{tabular}{lccc}
\hline Sample & $\begin{array}{c}\text { Trypsin added / } \\
\left.(\mathrm{nmol} \mathrm{L})^{-1}\right)\end{array}$ & $\begin{array}{c}\text { Trypsin found / } \\
(\mathrm{nmol} \mathrm{L})^{-1}\end{array}$ & $\begin{array}{c}\text { Recovery / } \\
\%\end{array}$ \\
\hline plasma 1 & 0 & - & - \\
plasma 2 & 5 & $4.9 \pm 0.02$ & 98 \\
plasma 3 & 10 & $9.7 \pm 0.04$ & 97 \\
plasma 4 & 15 & $14.8 \pm 0.04$ & 99 \\
\hline
\end{tabular}

aean of three determinations. 
recoveries of spiked trypsin in the diluted human blood plasma ranged from 97 to $99 \%$, thus demonstrating the potential applicability of the BSA-Au nanoclusters as fluorescence probe for the quantitative detection of trypsin in biological samples.

\section{Conclusions}

In summary, a sensitive, selective and simple fluorescent method for detection of trypsin activity using BSA-Au nanoclusters was developed. The mechanism is based on enzymolysis of the BSA-Au nanoclusters templates. A linear calibration plot for trypsin is in the range of 1 to $60 \mathrm{nmol} \mathrm{L} \mathrm{L}^{-1}$ with a limit of detection of $0.6 \mathrm{nmol} \mathrm{\textrm {L } ^ { - 1 }}$, and the $\mathrm{K}_{\mathrm{m}}$ and $\mathrm{K}_{\text {cat }}$ values are $1.6 \times 10^{-5} \mathrm{~mol} \mathrm{~L}^{-1}$ and $3.8 \mathrm{~s}^{-1}$ at $37{ }^{\circ} \mathrm{C}$, respectively. Furthermore, the present fluorescent method is also promising for the detection of other proteases by using target-specific peptide stabilized fluorescent metal nanoclusters.

\section{Acknowledgments}

This work was financially supported by the Science and Technology Department of Sichuan Province (N. 2011JY0134) and the Education Department of Sichuan Provincial (N.10ZC086).

\section{References}

1. Turk, B.; Nat. Rev. Drug Discovery 2006, 5, 785.

2. Farmer, W. H.; Yuan, Z.; Anal. Biochem. 1991, 197, 347.

3. Baustert, J. H.; Wolfbeis,O. S.; Moser, R.; Koller, E.; Anal. Biochem. 1988, 171, 393.

4. Matayoshi, E.; Wang, G.; Krafft, G.; Erickson, J.; Science 1990, 247, 954.

5. Cai,Q.Y.; Wang, R. H.; Wu, L. Y.; Nie, L. H.; Yao, S. Z.; Microchem. J. 1997, 55, 367.

6. Lefkowitz, R. B.; Marciniak, J. Y.; Hu, C. M.; SchmidSchonbein, G. W.; Heller, M. J.; Electrophoresis 2010, 31, 403.

7. Shimura, K.; Matsumoto, H.; Kasai, K.; Electrophoresis 1998, 19, 2296.

8. Eisenstein, M.; Nat. Methods 2005, 2, 6.

9. Cui, R.; Liu, H. -H.; Xie, H. Y.; Zhang, Z. L.; Yang, Y. R.; Pang, D. W.; Xie, Z. X.; Chen, B. B.; Hu, B.; Shen, P.; Adv. Funct. Mater. 2009, 19, 2359.

10. Xie, J. P.; Zheng, Y. G.; Ying, J. Y.; J. Am. Chem. Soc. 2009 , 131,888 .

11. Chen,W. B.; Tu, X. J.; Guo, X. Q.; Chem. Commun. 2009, 1736.

12. Jin, L.; Shang, L.; Guo, S.; Fang, Y.; Wen, D.; Wang, L.; Yin, J.; Dong, S. J.; Biosens. Bioelectron. 2011, 26, 1965.

13. Ahn,T.; Kim, J. S.; Choi, H. I.; Yun, C. H.; Anal. Biochem. 2002, 306, 247.

14. Finehout, E. J.; Cantor, J. R.; Lee, K. H.; Proteomics 2005, 5, 2319. 